\title{
Breed differences in the pharmacokinetics of ivermectin administered subcutaneously to Holstein and Belgian Blue calves
}

\author{
Jozef Vercruysse $^{\mathrm{a}, *}$, Piet Deprez ${ }^{\mathrm{b}}$, Dries Everaert ${ }^{\mathrm{b}}$, \\ Firas Bassissi ${ }^{c}$, Michel Alvinerie ${ }^{\mathrm{c}}$ \\ a Department of Virology, Parasitology and Immunology, Ghent University, Faculty of Veterinary Medicine, \\ Salisburylaan 133, B9820 Merelbeke, Belgium \\ ${ }^{\mathrm{b}}$ Department of Large Animal Internal Medicine, Ghent University, Faculty of Veterinary Medicine, \\ Salisburylaan 133, B9820 Merelbeke, Belgium \\ ${ }^{\mathrm{c}}$ Laboratory of Pharmacology-Toxicology, INRA-Toulouse BP3, Toulouse 31931 France
}

Received 26 September 2007; received in revised form 20 November 2007; accepted 26 November 2007

\begin{abstract}
Belgian Blue (BB) cattle are very sensitive to mange caused by Psoroptes ovis and, in contrast to the case in Holstein cattle, single treatments with ivermectin do not result in complete elimination of the parasite. The objective of the present study was to determine the concentration of ivermectin in plasma, skin and hair following subcutaneous administration to Holstein and BB calves and to assess the influence of breed on drug pharmacokinetics and availability. Two groups of six healthy female Holstein and $\mathrm{BB}$ calves were treated with ivermectin (SC formulation) at a dose of $0.2 \mathrm{mg} / \mathrm{kg}$. Blood, skin and hair were collected before treatment and up to 21 days after treatment. Ivermectin was analyzed in plasma and tissue by high-performance liquid chromatography (HPLC). The peak concentrations $\left(C_{\max }\right)$, time-peak concentrations $\left(T_{\max }\right)$, the area under the plasma concentration-time curves (AUC) and the mean residence time (MRT) were determined. The patterns of plasma and tissue ivermectin concentrations were similar in the two breeds of animals, however, the AUC and $C_{\max }$ levels for plasma and skin were significantly higher in the BB calves. In hair, ivermectin was detected later than in plasma and skin, with the $T_{\max }$ ranging between 4 days (Holstein group) and 6 days (BB group). The possible reasons for the significantly higher levels in plasma and skin in BB calves compared to Holstein calves are discussed.
\end{abstract}

(C) 2007 Elsevier B.V. All rights reserved.

Keywords: Ivermectin; Pharmacokinetics; Holstein; Belgian Blue; Cattle

\section{Introduction}

The clinical efficacy of ivermectin and the other macrocyclic lactones (MLs) is closely related to their

\footnotetext{
* Corresponding author at: Faculty of Veterinary Medicine, Ghent University, Salisburylaan 133, B-9820 Merelbeke.

Tel.: +3292647390; fax:+3292647496.

E-mail address: jozef.vercruysse@ugent.be (J. Vercruysse).
}

pharmacokinetic behaviour. The length of time during which parasites are exposed to active drug concentrations is important in determining optimal antiparasitic activity (Hennesy and Alvinerie, 2002). Research on the plasma kinetics and on the comparative plasma and target tissue disposition kinetics (Lanusse et al., 1997; Lifschitz et al., 1999, 2000) of ivermectin has contributed greatly to the understanding of the pharmacokinetics of the MLs. Several factors, such 
as animal species, level of feed intake and body composition, have been shown to affect the systemic availability of ivermectin substantially (Hennesy and Alvinerie, 2002) in both sheep and cattle. Moreover, important differences have been observed between the pattern of absorption and systemic availability of another ML - moxidectin - following topical administration in cattle of two different breeds, Aberdeen Angus and Holstein (Sallovitz et al., 2002). It has also been shown that the availability of ivermectin after subcutaneous injection is low in zebu Gobra cattle (Bos indicus) in comparison to other taurine (Bos taurus) breeds of cattle (Ndong et al., 2005).

Belgian Blue (BB) cattle appear to be very sensitive to Psoroptes ovis (Losson et al., 1999) and, unlike the case in cattle of the Holstein (and other breeds), single treatments with ivermectin do not always result in complete elimination of the parasite (unpublished results). The reason for this reduced efficacy is unknown, but a possible explanation is that differences in the systemic availability of ivermectin could lead to a lower exposure of parasites to the drug in BB calves compared to Holstein calves.

The objective of the present study was to determine the plasma, skin and hair pharmacokinetics of ivermectin after subcutaneous administration to Holstein and BB calves and to assess the influence of the animal's breed on drug availability. Skin and hair were included in the kinetic studies as the efficacy of the MLs against ectoparasites in animals largely depends on the distribution of the drug in the peripheral tissues (e.g. skin) (Hennesy and Alvinerie, 2002). It has also been demonstrated in humans that the efficacy of ivermectin against scabies largely depends on its secretion in sebum (Haas et al., 2002).

\section{Materials and methods}

\subsection{Animals}

Two groups of six healthy female Holstein and BB calves were used. The Holstein calves were between 5 and 6 months old and weighed between 147 and $181 \mathrm{~kg}$, the BB calves were between 5 and 9 months old and weighed between 153 and $283 \mathrm{~kg}$.

\subsection{Experimental design}

On day 0 all calves were treated with ivermectin (Ivomec ${ }^{\mathbb{R}}$, Merial Belgium N.V., SC formulation) at a dose of $0.2 \mathrm{mg} / \mathrm{kg}$ subcutaneously in the neck on the right side. Blood was collected in heparin tubes
(Venoject ${ }^{\circledR}$, lithium heparin, Terumo) before treatment (day 0 ) and $12 \mathrm{~h}, 1,2,4,8,10,12,14,18$ and 21 days after treatment. Hair and skin (at least $1 \mathrm{~g} / \mathrm{animal}$ ) were collected before treatment and at 1, 4, 8, 14 and 21 days after treatment. Hair was collected alternating on the left and right side of the back with a clipper (blade size $\mathrm{nr}$ 40). Skin samples were taken from the clipped areas. A ring block was applied around the biopsy site with 5 to $7 \mathrm{ml}$ of procaine $\mathrm{HCl} 4 \%$ (VMD, Belgium) and a full thickness skin sample (approximately $2 \mathrm{~cm}^{2}$ ) was excised. Subcutaneous fat tissue, if present, was removed from the sample, excess blood was drained by placing the sample on a sterile compress and the biopsy site was sutured with Dexon ${ }^{\mathbb{R}} 2-0$. Fluids and tissue samples were stored at $-20{ }^{\circ} \mathrm{C}$.

\subsection{Analytical procedures}

Residues of ivermectin in biological fluids are stable for up to one year after freezing (Cerkvenik et al., 2004) and the analysis of ivermectin in the fluids and tissues was performed within 3 months of collection. Ivermectin was analyzed in plasma and tissue by high-performance liquid chromatography (HPLC) with automated solid phase extraction and fluorescence detection according to a previously described method (Lifschitz et al., 2000). Briefly, fluid or tissue sample aliquots were homogenized in acetonitrile (Ultra Turrax T25 basic, Labortechnik). The homogenate was mixed $20 \mathrm{~min}$, sonicated $10 \mathrm{~min}$ (Ultrasound Bath) and centrifuged at $2000 \times g$ for $2 \mathrm{~min}$. The supernatant obtained was submitted to an automated phase extraction and placed on a Benchmate apparatus (BenchMate II, Zymark, Hopkinton, MA, USA) (Alvinerie et al., 1998). Fluorescent derivative was obtained by dissolving the eluent in $\mathrm{N}$-methylimidazole and trifluoroacetic anhydride (Aldrich, Milwaukee, WI, USA) solutions in acetonitrile. The chromatographic conditions included a mobile phase of acetic acid 2\%, methanol, acetonitrile $(4: 32: 64, \mathrm{v} / \mathrm{v} / \mathrm{v})$ pumped at a flow rate of $1.5 \mathrm{ml} / \mathrm{min}$ through a Supelcosil C18, $3 \mu \mathrm{m}$ column $(150 \mathrm{~mm} \times 4.6 \mathrm{~mm})$ (Supelco, Bellefonte, PA, USA). Fluorescence detection (Detector RF 551, Shimadzu, Kyoto, Japan) was performed at $365 \mathrm{~nm}$ excitation and $475 \mathrm{~nm}$ emission wavelength. The validation of the technique was performed by using drug free calf plasma, hair or skin tissue that were fortified with ivermectin in the range of $0.1-50.0 \mathrm{ng} / \mathrm{g}$ for plasma (Lanusse et al., 1997) and $0.5-50.0 \mathrm{ng} / \mathrm{ml}$ for both tissues (Lifschitz et al., 2000). In the plasma, the recovery of the technique was $77.7 \pm 8.8 \%$, the linearity was $r=0.99$ over a 0.1 $50.0 \mathrm{ng} / \mathrm{ml}$ concentration range $(n=6)$, the coefficient of variation $(\mathrm{CV})$ was 4.1 and the limit of quantitation 
(LOQ) was $0.05 \mathrm{ng} / \mathrm{ml}$. In the skin and in hair, the recoveries were $76.8 \pm 13.2 \%$, and $75.5 \pm 8.9 \%$, respectively, the linearity $r=0.99(0.5-50.0 \mathrm{ng} / \mathrm{g}, n=4)$ was very close for the two tissues, the CVs were 6.3 and 11.0 , LOQ was $0.1 \mathrm{ng} / \mathrm{g}$, similar for the three tissues.

\subsection{Pharmacokinetic and statistical analysis of the data}

The peak concentrations $\left(C_{\max }\right)$ and time-peak concentrations $\left(T_{\max }\right)$ were read from the plotted concentration-time curve for each animal. The area under the plasma concentration-time curves (AUC) from time zero to the last time $t$ with a measurable concentration $\left(C_{\mathrm{p}}\right)$ were calculated using the linear trapezoidal rule. The mean residence time (MRT) was calculated using the linear trapezoidal rule with extrapolation to infinity (Kinetica $4.4 .1^{\mathbb{R}}$, Thermo Electron Corporation, Waltham, USA), using the formula:

$\mathrm{MRT}=\frac{\mathrm{AUMC}}{\mathrm{AUC}}$

where AUMC is the area under the momentum curve and AUC the area under the plasma concentration-time curves from zero to infinity, as previously defined. The pharmacokinetic parameters are reported as mean \pm standard deviation. Data were subjected to statistical analysis using Kruskal-Wallis test performed with the Instat 2.01 software (Graph PAD, San Diego, USA). Values were considered significantly different at $P<0.05$.

\section{Results}

The plots of the mean plasma, skin and hair concentration versus time of ivermectin after subcutaneous administration of $0.2 \mathrm{mg} / \mathrm{kg}$ are shown in Figs. 1-3, respectively. The pharmacokinetic para-

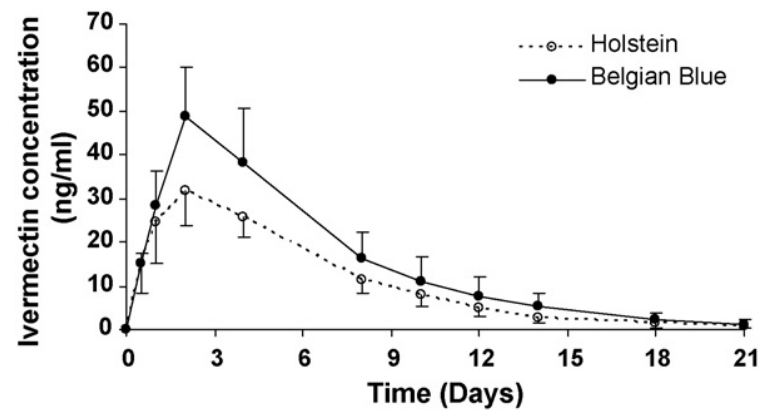

Fig. 1. Concentration-time profile (plasma) of subcutaneous administered ivermectin in Holstein or BB calves at dose rate of $0.2 \mathrm{mg} \mathrm{kg}^{-1}$.

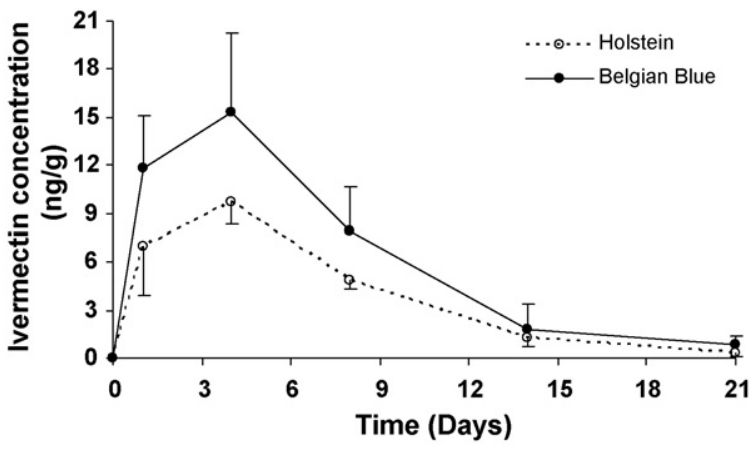

Fig. 2. Concentration-time profile (skin) of subcutaneous administered ivermectin in Holstein or BB calves at dose rate of $0.2 \mathrm{mg} \mathrm{kg}^{-1}$.

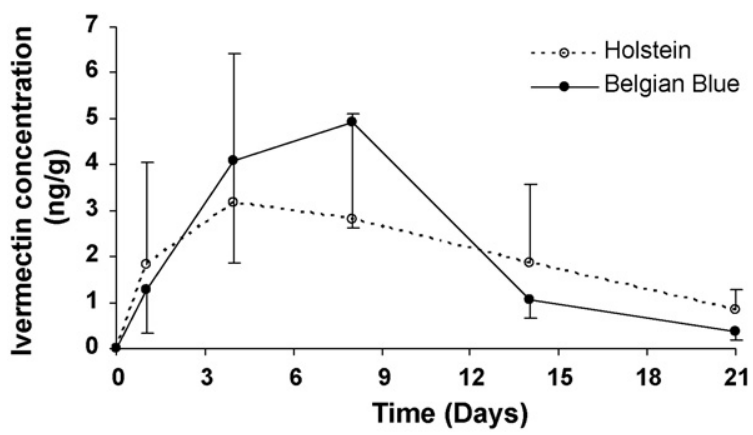

Fig. 3. Concentration-time profile (hair) of subcutaneous administered ivermectin in Holstein or BB calves at dose rate of $0.2 \mathrm{mg} \mathrm{kg}^{-1}$.

meters that describe the disposition of ivermectin are reported in Tables 1-3 for plasma, skin and hair, respectively.

In plasma, ivermectin concentration was maximal the 2nd day post-treatment and decreased slowly with time. By day 21 post-treatment, the residual plasma concentrations were low in both groups $(0.5-1.0 \mathrm{ng} /$ $\mathrm{ml}$ ). Fig. 1 shows a parallel plasma profile for the two groups of animals, with higher plasma levels in BB calves, resulting in significantly higher area plasma concentration versus time curve (AUC) and maximal plasma concentration $\left(C_{\max }\right)$ as reported in Table 1. In skin ivermectin was detected at the first sampling time (day 1) and reached a maximal level on in the sample

Table 1

Plasma pharmacokinetic parameters of ivermectin in Holstein and BB calves after a single subcutaneous administration at dose rate of $0.2 \mathrm{mg} \mathrm{kg}^{-1}$

\begin{tabular}{lcc}
\hline Parameter & Holstein $(n=6)$ & Belgian Blue $(n=6)$ \\
\hline $\mathrm{AUC}_{0 \text {-last }}\left(\mathrm{ng} \mathrm{day} \mathrm{ml}^{-1}\right)$ & $224.24 \pm 27.58$ & $328.43 \pm 52.48$ \\
$\left.C_{\max }(\mathrm{ng} \mathrm{ml})^{-1}\right)$ & $31.87 \pm 7.23$ & $49.51 \pm 10.76$ \\
$T_{\max }($ days $)$ & $1.83 \pm 0.37$ & $2.33 \pm 0.75$ \\
$T_{\text {half }}($ days $)$ & $3.00 \pm 0.57$ & $3.17 \pm 0.84$ \\
MRT total (days) & $5.80 \pm 1.14$ & $6.16 \pm 1.87$ \\
\hline
\end{tabular}


Table 2

Skin pharmacokinetic parameters of ivermectin in Holstein and BB calves after a single subcutaneous administration at dose rate of $0.2 \mathrm{mg} \mathrm{kg}^{-1}$

\begin{tabular}{lcc}
\hline Parameter & Holstein $(n=6)$ & Belgian Blue $(n=6)$ \\
\hline $\mathrm{AUC}_{\text {-last }}\left(\right.$ ng day g $\left.^{-1}\right)$ & $81.28 \pm 7.71$ & $126.62 \pm 17.46$ \\
$C_{\max }\left(\mathrm{ng} \mathrm{g}^{-1}\right)$ & $9.93 \pm 1.67$ & $15.01 \pm 4.36$ \\
$T_{\max }$ (days) & $3.5 \pm 1.22$ & $5.33 \pm 2.07$ \\
$T_{\text {half }}$ (days) & $3.0 \pm 0.60$ & $3.15 \pm 1.04$ \\
MRT total (days) & $6.48 \pm 1.17$ & $5.69 \pm 1.35$ \\
\hline
\end{tabular}

Table 3

Hair pharmacokinetic parameters of ivermectin in Holstein and BB calves after a single subcutaneous administration at dose rate of $0.2 \mathrm{mg} \mathrm{kg}^{-1}$

\begin{tabular}{lcc}
\hline Parameter & Holstein $(n=6)$ & Belgian Blue $(n=6)$ \\
\hline $\mathrm{AUC}_{0-\text { last }}\left(\right.$ ng day g $\left.^{-1}\right)$ & $51.57 \pm 37.42$ & $58.65 \pm 18.80$ \\
$C_{\max }\left(\right.$ ng g $\left.^{-1}\right)$ & $4.10 \pm 3.42$ & $5.96 \pm 2.27$ \\
$T_{\max }($ days $)$ & $4.57 \pm 2.09$ & $6.67 \pm 2.07$ \\
$T_{\text {half }}$ (days) & $7.25 \pm 1.67$ & $4.03 \pm 1.99$ \\
MRT total (days) & $9.55 \pm 2.91$ & $19.51 \pm 13.12$ \\
\hline
\end{tabular}

taken on the 4th day post-treatment. As observed for plasma the maximal skin levels were significantly higher in BB calves $\left(C_{\max }: 126.62 \pm 17.46\right)$ compared to Holstein calves $\left(C_{\max }: 81.28 \pm 7.71\right)$. Fig. 2 shows the skin concentration profiles, which are similar to the plasma concentration profiles, but with a lower concentration range. In hair ivermectin was detected later than in plasma and skin, with a $T_{\max }$ of 4 days in the Holstein group and 6 days in the BB group (Table 3).

\section{Discussion}

For both breeds, we observed a parallel distribution of ivermectin in skin and plasma, due to the continual exchange of drug between the two tissues, as previously described by others (Lifschitz et al., 2000). The ivermectin concentrations in the target tissues were lower in the Holstein group compared with BB group, in agreement with the observed differences in plasma concentrations. The ivermectin distribution in hair probably originates via sebum secretion, as previously reported in humans with scabies after oral treatment with ivermectin (Haas et al., 2002). This feature probably accounts for the high efficacy of ivermectin against ectoparasites.

In the current trial the systemic availability of ivermectin was statistically different between the two cattle breeds studied. In cattle, breed and race differences in drug kinetics have been reported in the past (Ndong et al., 2005; Sallovitz et al., 2002). Important differences in the pattern of systemic availability of moxidectin after topical administration have been observed between Aberdeen Angus and Holstein breeds (Sallovitz et al., 2002). Differences in skin physiology, inherent to these breeds, were suggested as a possible explanation for the different systemic availability. In the present study ivermectin was administered subcutaneously and therefore our results suggest that factors other than skin physiology may affect pharmacokinetic differences between breeds. The pharmacokinetic behaviour of subcutaneously administered ivermectin has been investigated in West African breeds cattle (Ndong et al., 2005) and the AUC for ivermectin in zebu Gobra cattle was lower in comparison to other cattle breeds, presumably due to specific anatomical or physiological characteristics of this breed.

However, the reasons for the significantly higher levels in plasma and skin in BB calves group compared to Holstein calves are difficult to explain. For a given drug formulation administered by a certain route, many animal-related factors will determine differences in pharmacokinetic behaviour. Among these factors differences in body composition have been suggested as a cause of differences in ivermectin pharmacokinetics between individuals and species due to the highly lipophilic nature of the drug. The higher fat content of Holstein carcasses compared to BB carcasses $(28.3 \%$ versus $15.4 \%$, Istasse et al., 1990) might explain the difference in peak plasma concentrations $\left(C_{\max }\right)$. In fact, injected ivermectin could have accumulated in the fat of the subcutaneous injection site in the Holstein calves, while injected ivermectin in the BB cattle could have reached directly the systemic circulation. A faster absorption could explain the higher value of the AUC in BB calves compared to Holstein calves. The elimination process, however, was quite similar in the two breeds, as indicated by the elimination half-life values. This corresponds with previous results demonstrating that in cattle metabolism of ivermectin is limited and that the major excretion product in faeces is the parent compound (Chiu et al. (1987). Therefore, a possible difference in metabolism between Holstein and BB seems unlikely.

The binding of drugs to plasma components is also a determinant of interest in the pharmacokinetic profile. The plasma binding of ivermectin and other related macrocyclic lactones is mainly due to association with high-density lipoproteins (HDL) (Bassissi et al., 2004) whereas binding to albumin is of minor importance (Audus et al., 1992). In various animal species (cattle, 
sheep, goat, rabbit, pig) no difference in the binding pattern of MLs to lipoproteins was reported (Bassissi et al., 2004), consequently this is unlikely to be the cause of the breed differences in pharmacokinetics.

The minimal concentration of ivermectin required at the target tissues (e.g. skin) to inhibit the development of parasites (e.g. scabies) has not been determined. However, the higher concentration of ivermectin in BB, compared to Holstein calves, suggests that the lower efficacy of ivermectin against psoroptic mange is not related to drug availability at the target site. A different skin reaction pattern against P. ovis in BB cattle compared to Holstein cattle could also explain the apparent reduced efficacy of ivermectin in this breed. Losson et al. (1999) showed that an intradermal injection of Psoroptes cuniculi antigen in P. ovis-infected BB and Holstein cattle resulted in a delayed hypersensitivity reaction only in BB cattle. This may explain the more severe and prolonged skin reactions observed in this breed during a Psoroptes infestation.

\section{References}

Alvinerie, M., Escudero, E., Sutra, J., Eeckhoutte, C., Galtier, P., 1998. The pharmacokinetics of moxidectin after oral and subcutaneous administration to sheep. Vet. Res. 29, 113-118.

Audus, K., Knaub, S., Guillot, F., Schaeffer, J., 1992. The effect of protein binding on ivermectin uptake by bovine brain microvessel endothelial cells. Vet. Res. Comm. 16, 365-377.

Bassissi, M.F., Alvinerie, M., Lespine, A., 2004. Macrocyclic lactones: distribution in plasma lipoproteins of several animal species including humans. Comp. Biochem. Physiol. C. Toxicol. Pharmacol. 138, 437-444.
Cerkvenik, V., Perko, B., Rogelj, I., Doganoc, D., Skubic, V., Beek, W., Keukens, H., 2004. Fate of ivermectin residues in ewe's milk and derived products. J. Dairy Res. 71, 39-45.

Chiu, S.H.L., Taub, R., Sestokas, E., Lu, A.Y.H., Jacob, T.A., 1987. Comparative in vivo and in vitro metabolism of ivermectin in steers, sheep, swine and rats. Drug Metab. Rev. 18, 289-302.

Haas, N., Lindemann, U., Frank, K., Sterry, W., Lademann, J., Katzung, W., 2002. Rapid and preferential sebum secretion of ivermect: a new factor that may determine drug responsiveness in patients with scabies. Arch. Dermatol. 138, 1618-1619.

Hennesy, D., Alvinerie, M., 2002. Pharmacokinetics of the macrocyclic lactones: conventional wisdom and new paradigms. Chapter 2. In: Vercruysse, J., Rew, R. (Eds.), Macrocyclic Lactones in Antiparasitic Therapy. CAB (ISBN: 085199617 5), pp. 97-124.

Istasse, L., Van Eenaeme, C., Evrard, P., Gabriel, A., Baldwin, P., Maghuin-Rogister, G., Bienfait, J., 1990. Animal performance, plasma hormones and metabolites in Holstein and Belgian Blue growing-fattening bulls. J. Anim. Sci. 68, 2666-2673.

Lanusse, C., Lifschitz, A., Virkel, G., Alvarez, L., Sanchez, S., Sutra, J., Galtier, P., Alvinerie, M., 1997. Comparative plasma disposition kinetics of ivermectin, moxidectin and doramectin in cattle. J. Vet. Pharmacol. Ther. 20, 91-99.

Lifschitz, A., Virkel, G., Imperiale, F., Sutra, J., Galtier, P., Lanusse, C., Alvinerie, M., 1999. Moxidectin in cattle: correlation between plasma and target tissues disposition. J. Vet. Pharmacol. Ther. 22, 266-273.

Lifschitz, A., Virkel, G., Sallovitz, J., Sutra, J., Galtier, P., Alvinerie, M., Lanusse, C., 2000. Comparative distribution of ivermectin and doramectin to parasite location tissues in cattle. Vet. Parasitol. 87, 327-338.

Losson, B., Lonneux, J., Lekimme, M., 1999. The pathology of Psoroptes ovis infestation in cattle with a special emphasis on breed difference. Vet. Parasitol. 83, 219-229.

Ndong, T.B., Kane, Y., Ba, M., Sane, I., Sutra, J., Alvinerie, M., 2005. Pharmacokinetics of ivermectin in zebu Gobra (Bos indicus). Vet. Parasitol. 128, 169-173.

Sallovitz, J., Lifschitz, A., Imperiale, F., Pis, A., Virkel, G., Lanusse, C., 2002. Breed differences on the plasma availability of moxidectin administered pour-on to calves. Vet. J. 164, 47-53. 